\title{
Facilitating word-fragment completion with hidden primes
}

\author{
STEPHEN MADIGAN, JOAN MCDOWD, and DANA MURPHY \\ University of Southern California, Los Angeles, California
}

\begin{abstract}
(Joseph B. Hellige, Sponsor)
Two experiments tested the effectiveness of priming on word-fragment completion when the priming operation consisted of the presentation of target words in the instructions for the fragmentcompletion task. Reliable priming effects were obtained in both experiments. The second experiment also examined the influence of case change of printed materials on the extent of priming effects. No simple outcome occurred, as the effects of case change or constancy were not symmetrical with respect to upper- and lowercase.
\end{abstract}

This paper reports the results of two experiments on priming effects in a word-fragment-completion task. The experiments dealt with the following question: Would word-fragment completion be facilitated by a priming event that consisted of the presentation of some of the target words in the instructions for the fragment-completion task? We came to ask this question after reading Schacter's (1987) review of implicit-memory research. Schacter discusses a possible difficulty with the usual way of producing repetition priming effects. In the typical procedure, a list of words is presented under some instructional or task conditions. Later, subjects are given a task, such as word-fragment completion or perceptual processing, in which some of the previously presented words occur as targets. Schacter's concern was that subjects might "catch on": To aid their performance in the second task, they might come to rely on either episodic retrieval or scanning of memory from the initial word list.

Schacter notes that various procedures have been employed to minimize this possibility, such as testing only a small proportion of list words or generally attempting to disguise the relationship between the two tasks. It occurred to us that one simple approach to this problem might be to do away with the presentation of a word list altogether and, instead, prime target words by putting them in the instructions for the experimental task. We felt that this procedure would greatly reduce the possibility that subjects would or could systematically attempt episodic retrieval, especially if the number of words so primed was small. The two experiments reported here clearly show that priming effects can be obtained under such conditions.

A report of this research was presented at the annual meeting of the Western Psychological Society, May 1990, Los Angeles, California. Correspondence should be addressed to Stephen Madigan, Department of Psychology, University of Southern California, Los Angeles, CA 90089-1061.

\section{EXPERIMENT 1}

Experiment 1 was conducted partly as a filler task in connection with another (unrelated) experiment and partly as a classroom-demonstration experiment. It was a simple comparison of word-fragment completion for primed and unprimed words, with the priming consisting of the presentation of some target words in the task instructions.

\section{Method}

Procedure. The subjects were given a two-page booklet and asked to read the instructions for a word-fragment-completion task on the first page. Different subjects read one of the two following sets of instructions:

Form A

This test is a word-fragment-completion task. You will be given a collection of words with some letters missing. Your task is to find the missing letters. For example: $c_{-} o_{-} e_{-}=$closet.

You can take up to 5 minutes to complete the task. When you think of a word for a word fragment, write it down on the line opposite the word fragment.

Form B

This test procedure is a word-fragment-completion task. You will be given a set of words with some letters missing. Your task is to discover the missing letters. For example: $c_{-} o_{-} e_{-}=$closet.

You can take up to 5 minutes to finish the task. When you think of a solution for a word fragment, write it down on the line beside the word fragment.

In Form A, the words collection, complete, and opposite were the primed target words. (Of course, they were not italicized in the actual experimental materials.) In the word-fragment test, these three words occurred along with three unprimed words, procedure, discover, and solution. Form $B$ of the instructions provided a counterbalancing of these item sets against priming condition. The word-fragment test always contained these six words for all subjects, along with six filler words.

In the fragment-completion task, the subjects were given a sheet of paper with 12 word frames on it and were allowed up to $5 \mathrm{~min}$ to complete as many as possible. The frames always consisted of blank-letter alternation. For example, the target word solution was presented as _o_u_i_n.

Subjects. Eighty-five college students were tested with this procedure by random assignment to Forms $\mathrm{A}$ or $\mathrm{B}$.

\section{Results}

The results are easy to describe: There was a reliable priming effect. Table 1 shows the percentage of correct 
Table 1

Percentage of Correct Word-Fragment Completions in Experiment 1

\begin{tabular}{ccc}
\hline Target Word & Primed & Unprimed \\
\hline collection & 29.5 & 22.0 \\
complete & 31.8 & 17.1 \\
opposite & 70.5 & 65.9 \\
procedure & 31.7 & 18.2 \\
discover & 51.2 & 18.2 \\
solution & 41.5 & 31.8 \\
\hline
\end{tabular}

Note $-N=85$.

fragment completions for each of the critical words when they were used as primed words and when they were used as unprimed controls. A priming effect is evident for all of the words used, although it clearly varies in size for different items. Overall, the magnitude of the priming effect seems comparable to those obtained in priming studies that used the usual list-priming procedure. The withinsubjects comparison of solution rates for primed and unprimed words was significant $[F(1,80)=14.597$, $p<.001]$.

\section{EXPERIMENT 2}

Experiment 2 was intended partly as a replication and refinement of the priming procedure and partly as a test of a substantive hypothesis. The experiment was based on the same kind of comparisons as were made in Experiment 1: word-fragment-completion performance for words primed or not primed, with priming occurring in task instructions. In addition to the basic priming variable, the experiment also included conditions intended to determine how priming effects might be affected by a change in the surface features of words between presentation and test. Previous research (Roediger \& Blaxton, 1987) has suggested that priming effects might be reduced or eliminated by changes in item format, results that have led to the suggestion that the procedural-memory system is characterized by "hyperspecificity of access"' (Tulving \& Schacter, 1990). Experiment 2 explored this question by changing the type case of words between priming and testing in some conditions and by keeping it constant in others. This was based on a crossing of case of presentation (upper, lower) by case of testing (upper, lower) for four different treatment groups.

\section{Method}

Procedure. The experimental materials for each subject consisted of a deck of 16 file cards. The first card recorded subject identification. The second card listed the word-fragment-task instructions. The rest of the deck consisted of word frames: 3 instruction-primed words, 3 nonprimed controls, and 8 filler words. This part of the card deck always started with 2 filler words followed by a random ordering of the critical and remaining filler items. As in Experiment 1, there were two forms of the instructions, with half of the subjects in each of four treatment groups receiving one form or the other.

The four treatment groups were formed from the crossing of the type case of instructions (upper, lower) and word fragments (upper, lower).
In uppercase instructions, all letters in all words were uppercase. In lowercase instructions, only the initial letter of the first word of each sentence was in uppercase.

Subjects. The subjects were 160 college students who were assigned at random to one of the four case conditions and instruction forms.

\section{Results}

Table 2 summarizes the priming effects for individual words. These data show a clear replication of the results of Experiment 1. All of the words led to better fragment completion as primes than as unprimed controls, again with considerable variation across words. The overall contrast of primed versus unprimed was significant $[F(1,159)$ $=11.804, p<.01]$.

The effect of change versus constancy of item format is described in Table 3, with conditions arranged from best to worst. The data indicate that all four priming conditions produced more solutions than did the two unprimed control conditions. The variation within the priming conditions presents a complicated picture. There was no simple case-constancy effect; although fragment completion was best with both primes and fragments in lowercase, performance with both in uppercase was poorer than it was with the lower-upper combination. The data could be summarized by saying that uppercase in the test phase was associated with poorer performance; this might be rationalized by the subjects' greater familiarity with lowercase letters from their normal reading experience. But the results for upper- and lowercase unprimed tests complicate any such interpretation, there being only a very small difference between lower- and uppercase control items. This apparent asymmetry in the effects of case change is not new. Roediger and Blaxton (1987) has reported an asymmetrical outcome with visual format changes, as have Hintzman and Summers (1973) in a study of episodic recognition memory.

Table 2

Percentage of Correct Word-Fragment Completions in Experiment 2

\begin{tabular}{ccc}
\hline Target Word & Primed & Unprimed \\
\hline research & 29.8 & 20.8 \\
complete & 33.3 & 29.2 \\
instruct & 35.7 & 20.8 \\
ordinary & 74.0 & 63.1 \\
solution & 42.9 & 36.9 \\
procedure & 26.0 & 4.8 \\
\hline
\end{tabular}

Note $-N=160$.

Table 3

Percentage of Word-Fragment Completions as a Function of Study-Test Case in Experiment 2

\begin{tabular}{ccc}
\hline Study Case & Test Case & \% Correct \\
\hline lower & lower & 46.2 \\
upper & lower & 41.9 \\
upper & upper & 36.6 \\
lower & upper & 35.1 \\
- & upper & 30.1 \\
- & lower & 29.1 \\
\hline
\end{tabular}




\section{DISCUSSION}

The two experiments indicate that reliable priming of word-fragment completion can occur with primes presented in task instructions, contrary to negative findings reported by Oliphant (1983) and by Levy and Kirsner (1989). MacLeod (1989) has also reported two successes with an incidental text-priming procedure. His results and our results (as well as those of a third experiment of ours in progress) indicate that there are conditions under which such priming is effective. This priming also seems to occur without the subjects' awareness of the connection between words in the instructions and word frames in the task, to judge from postexperiment questionnaires.

A final observation on priming procedures and effects: The priming experiments reported here could be regarded as studies of problem solving, as well as studies of memory. In fact, the problem-solving literature contains many different kinds of attempts to facilitate problem solving by presentation of "hints" and disguised prompts (e.g., Mednick, 1962). There may be some interesting intersections of methods and theories from studies of explicit and implicit memory and problem solving.

\section{REFERENCES}

Hintzman, D. L., \& Summers, J. L. (1973). Long-term visual traces of visually presented words. Bulletin of the Psychonomic Society, 1, 325-327.
LeVy, B. A., \& KirSner, L. (1989). Reprocessing text: Indirect measures of word and message level processes. Joumal of Experimental Psychology: Learning, Memory, \& Cognition, 15, 404-417.

MACLEOD, C. M. (1989). Word context during initial exposure influences degree of priming in word fragment completion. Journal of Experimental Psychology: Learning, Memory, \& Cognition, 15, 398-406.

Mednick, S. A. (1962). The associative basis of the creative process. Psychological Review, 69, 220-232.

Oliphant, G. W. (1983). Repetition and recency effects in word recognition. Australian Journal of Psychology, 35, 393-403.

Roediger, H. L., III, Blaxton, T. A. (1987). Effects of varying modality, surface features, and retention interval on priming in wordfragment completion. Memory \& Cognition, 15, 379-388.

SCHACTER, D. L. (1987). Implicit memory: History and current status. Journal of Experimental Psychology: Learning, Memory, \& Cognition, 13, 501-518.

Tulving, E., SCHaCter, D. L. (1990). Priming and human memory systems. Science, 247, 301-306.

(Manuscript received August 20, 1990.) 